\title{
Convenient or trendy: factors influencing consumption at Malaysian home-grown full- service restaurants
}

\begin{abstract}
Full-service restaurants have no geographical boundaries to limit the kinds of food and related services they offer in a rapidly growing global food industry. In Malaysia they are becoming especially visible in the urban areas where full-service restaurant operators including hawkers have recorded sustainable growth over the past few years. This study aims to explore factors that influence Malaysian consumers to patronize home-grown Malaysian full-service restaurants and seeks to investigate public opinion about those outlets. A survey was conducted using a self-administered questionnaire that was distributed randomly among 900 respondents in Klang Valley. Descriptive analysis, exploratory factor analysis, and binary logistic regression were employed to analyze collected information. The outcome from analysis shows the latent factors such as food quality and service.
\end{abstract}

Keyword: Convenience; Factor analysis; Home-grown full-service restaurants; Logistic regression; Patron 